\title{
Career Decision-making Difficulties, Dysfunctional Thinking and Generalized Self-Efficacy of University Students in Greece
}

\author{
Despina Sidiropoulou-Dimakakou (Corresponding author) \\ Faculty of Philosophy, Pedagogy and Psychology, University of Athens \\ Panepistimiopolis, 15784 Ilissia, Athens, Greece \\ Tel: 30-210-727-7571 E-mail: dsidirop@psych.uoa.gr
}

Kostas Mylonas

Faculty of Philosophy, Pedagogy and Psychology, University of Athens

Panepistimiopolis, 15784 Ilissia, Athens, Greece

Tel. 30-210-727-7584 E-mail: kmylonas@psych.uoa.gr

Katerina Argyropoulou

Faculty of Philosophy, Pedagogy and Psychology, University of Athens

Panepistimiopolis, 15784 Ilissia, Athens, Greece

Tel. 30-210-727-7571 E-mail: kargirop@otenet.gr

Sofia Tampouri, M.Sc.

Career Office, University of Piraeus

80-82 Zeas Str., 18534, Piraeus, Greece

Tel: 30-210-414-2534_E-mail: stampouri@unipi.gr

Received: July 12, 2011

doi:10.5430/wje.v2n1p117
Accepted: August 21, 2011

Published: February 1, 2012

\begin{abstract}
The present study aims to examine the relationship of career decision-making difficulties, dysfunctional career thoughts and generalized self-efficacy, as factors involved in the decision-making process for university students. The study also investigates the influence of demographics and individual variables, and examines the predictive power of the Career Decision-making Difficulties Questionnaire (CDDQ) and the Generalized Self-Efficacy Scale (GSE) over the dimensions assessed by the Career Thoughts Inventory (CTI).

The results revealed statistically significant positive correlations between CDDQ factors (lack of information, inconsistent information, and lack of readiness) and total grade in Career Thoughts Inventory (CTI), decision-making confusion, commitment difficulty and lack of determination. On the other hand, the results show statistically significant negative correlations between all the aforementioned variables and generalized self-efficacy. Moreover, the generalized self-efficacy, as well as the CDDQ factors seemed to be predictors of the lack of determination, decision-making confusion and commitment difficulty. Finally, there is a discussion about the additionality of the CDDQ and CTI Questionnaires and advantages from their common use. Findings are discussed in the terms of the career counseling framework.
\end{abstract}

Keywords: Career decision-making difficulties, Career thoughts, Generalized self-efficacy

\section{Introduction}

In recent years, career indecision has become an increasingly important construct in the field of vocational psychology (Kelly \& Lee, 2002). The concept of career indecision usually includes the individual's difficulties in his/her effort to 
make career decisions. These difficulties are traced either before or during the decision-making process, are divided into cognitive or emotional difficulties and hinder the decision-making process (Osipow, Carney \& Barak, 1976, cf Saka \& Gati, 2007; Sidiropoulou-Dimakakou, 2010).

Gati, Krausz \& Osipow (1996) developed a taxonomy of difficulties in career decision-making. In this taxonomy, the difficulties were defined as deviations from an "ideal career decision-maker"- a person who is aware of the need to make a career decision, willing to make such a decision and capable of making the decision "correctly". Any deviation from this model was considered as a potential difficulty that could affect the individual's decision-making process in one of two possible ways: (a) by preventing the individual from making a career decision or (b) by leading to a less optimal career decision. The taxonomy includes three major categories of difficulty: lack of readiness to engage in the career decision-making process, lack of information (about the self, about the steps involved in the process, about the various alternatives and the sources of additional information) and inconsistent information (unreliable information, internal and external conflicts).

Young people around the world, upon completion of their academic studies in a specific scientific field, find themselves in a difficult position, as they have to move to career decision-making. For many young people, career choice represents a difficult and complicated process that can detain a state of indecision with negative, long-termed consequences in their professional, personal and social life (Osipow, 1999).

Recent studies revealed that a significant proportion of university students are undecided about their career paths (Lee, 2005 ) and that career indecision is related to various cognitive factors, such as career decision-making, self- efficacy (Creed \& Patton, 2003), dysfunctional career thoughts (Sampson, Peterson, Lenz, Reardon \& Saunders, 1998), lack of information (Germeijs \& De Boeck, 2003), internal - external conflicts (Thompson \& Subich, 2006), self-knowledge (Gati \& Saka, 2001) and one's previous working experience (Lent, Brown, Talleyrand, McPartland, Davis, Chopra et al., 2002).

But, while each one of the above cognitive factors have separately been an object of numerous research (Saunders, Peterson, Sampson \& Reardon, 2000; Roll \& Arthur, 2002; Creed, Patton, \& Prideaux, 2006), their co-examination has not been attempted (Austin, 2005). In the current study, research is being conducted regarding the difficulties in career decision-making, the dysfunctional beliefs and the perception of self-efficacy, as cognitive factors related to the career indecision of University students.

\section{Career Decision-making Difficulties}

\subsection{Dysfunctional career thoughts}

The dysfunctional career thoughts have been recognized as an important factor in the career decision-making process (Austin, Wagner \& Dahl, 2003). They refer to prejudiced or twisted career beliefs, unreasonable expectations, various career myths, negative estimations regarding the individual's actions and professions, which influence each one's ambitions and his actions, leading to self-defeating experiences. For example, a person may erroneously attribute facts to his/her own self, while there is no rational base whatsoever for such a link. Thus, a person that has even intrinsically challenged the results of any skills test, can -by over-generalizing- reach the conclusion that all tools of career evaluation and the associated sources of information are a waste of time. Another person may perceive career alternatives either as perfectly satisfying or as globally inadequate (dichostatic thinking).

Such dysfunctional thoughts make the decision-making procedure harder and force the person to avoid it in its totality or to transfer the responsibility of choosing to significant others, jeopardizing this way one's overall career development. As a result, the individual may experience stress and lack of satisfaction from his/her choice, while one's self-estimation and trust to his/her ability on making important decisions is reduced (Krumboltz, 1994). In contrast, absence of negative and dysfunctional thoughts helps the individual to successfully combine his/her knowledge on him/herself and the business world (Saunders, Peterson, Sampson \& Reardon, 2000). According to Dryden (1979), a person that asks for career counseling rarely avoids at least one unreasonable idea associated with his ability to make career decisions.

\subsection{Lack of information}

Nathan \& Hill (2006) support that the individual who seeks career counseling often cannot easily reach a decision because he/she doesn't have the information needed to base his/her choice, or because he/she doesn't know him/herself. The lack of a well figured self-perception and the lack of knowledge regarding the elements that compose the individual's personality (Gati \& Saka, 2001), such as interests and abilities, drive the individual to confusion and hinder the decision-making process (Sampson, Peterson, Lenz, Reardon \& Saunders, 1998). Moreover, lack of information on occupations, alternative choices, and ways of acquiring information, but also the career decision process itself, constitute difficulties that are accompanied with irresolution in choosing an occupation (Germeijs \& De Boeck, 2003). Moreover, 
the lack of correct information regarding the labor market can provoke confusion. Sometimes, the information that one uses is not recent or is not suitably presented by their source, without excluding the case where he/she unconsciously manipulates the information because of his/hers personal stance, beliefs and values. Not infrequently, new information can change the individual's decisions (Sidiropoulou - Dimakakou, 1995).

\subsection{Internal - External conflicts}

In many cases, the person's efforts to make a specific career decision are interrupted because of the conflicts that are caused either by individual factors or by pressure from third parties or even by external factors, such as social, economic and political ones. Internal conflicts are of three types: a) Conflict of the type "approach-approach". This kind of conflict is experienced by the individual when he/she desires two contrasting things simultaneously and to the same extent. b) Conflict of the type "avoidance-avoidance". It is caused in circumstances where two contrasting things are undesirable simultaneously for the individual and to the same extent. c) Conflict of the type "approach-avoidance". It is expressed when the same object provokes attracting and compulsive force in the individual at the same time (Dimitropoulos, 2003). Moreover, the conflict between two different parts of the self, for example the creative and the conventional self, can lead the person to weakness in decision-making.

\subsection{Self-efficacy}

Bandura (1977) introduced the concept of self-efficacy with which he declared the individual's subjective judgment concerning his/her ability to succeed in an activity or to confront a situation. Therefore, self-efficacy does not refer to whether a person is objectively capable or not, but to his personal beliefs whether he has the necessary skills to do something, under various circumstances (Kantas \& Hantzi, 1991). According to the theory, the subjective estimation of the person's skills plays a decisive role in his vocational behavior (Bandura, 1997).

Research highlights the decisive effect of self-efficacy perceptions in career decision-making and in the articulated choices (Lent \& Hackett, 1994). The higher the self-efficiency level people have concerning the fulfillment of their vocational roles, the higher interest displayed for the certain choices and the greater their persistence in following their career goals (Bandura, Barbaranelli, Caprara \& Pastorelli, 2001). Low perception of self-efficacy in the career decision-making blocks the individual from being engaged in possible career choices (Betz \& Serling, 1995, cf Betz \& Luzzo, 1996). According to other research, young people that feel capable of successfully passing the procedure of career decision-making perceive less personal or external obstacles in the aforementioned procedure (McWhirter, Rasheed \& Crothers, 2000) and show certainty in career choices (Argyropoulou, Sidiropoulou-Dimakakou \& Besevegis 2007; Betz, Klein \& Taylor, 1996). Indeed, Betz $\kappa \alpha$ l Voyten (1997) defined self-efficacy, regarding career decision-making, as the most powerful forecasting factor for career indecision.

\section{The Present Study}

The primary goal of the present study was to examine the relationship among career decision-making difficulties, dysfunctional career thoughts and generalized self-efficacy in a sample of University students. The second goal was to investigate how the previous variables are differentiated under the influence of specific demographic and individual variables. Finally, the present study aims to explore the possibility of predicting the Career Thoughts Inventory questionnaire factors by the Career Decision-making Difficulties Questionnaire and the Generalized Self-Efficacy factors; this last aim is a form of a criterion related validity attempt, resembling concurrent validity testing (Anastasi, 1990). The instruments employed in the present study are presented fully in the method section which follows.

\section{Method}

\subsection{Participants}

The sample of the study consisted of 260 final-year students of the University of Piraeus ( $\mathrm{N}=260)$ from whom 88 (33.8\%) were males and $172(66.2 \%)$ were females. The female over-representation is partly a result of the sampling method (reported later in the "Procedure" section). From the total sample, 205 (78.8\%) declared that they had some form of occupational experience; in respect to whether they had received support by Career Guidance Services, the majority of the sample $(68.5 \%)$ replied negatively. Furthermore, $217(83.5 \%)$ declared that the vocational domain linked to their Degree matched their interests. Finally, 159 students $(61.2 \%)$ reported that they had not received any specific professional decision and among these, the majority (86.8\%) reported finding it difficult to make a career decision. At the same time, out of the 101 students $(38.8 \%)$ having made a particular career decision, the majority (58.4\%) reported finding it difficult to make a career decision. 


\subsection{Instrumentation}

For the data collection, a number of questionnaires were employed:

(a) Career Thoughts Inventory (CTI) (Sampson, Peterson, Lenz, Reardon \& Saunders, 1996; Kassotakis, Sidiropoulou-Dimakakou \& Papadakou, 2005)

Career Thoughts Inventory is composed by 48 items, scored on a four-point Likert type scale by the respondents. An overall score is calculated, quantifying the level of existence of dysfunctional thoughts in an individual. Three separate scores that determine the type, the characteristics and the thoughts that people express are also calculated. These are achieved through the three following sub-scales: a) Decision-making Confusion - DMC scale (14 items), which refers to the individual's weakness to put into practice or to maintain the career decision-making process, as a result of weak feelings, lack of understanding of the career decision-making process itself and/or lack of capacity to combine the knowledge for him/herself with the knowledge for the professional world, b) Commitment Anxiety - CA scale (10 items), which counts the individual's weakness to commit him/herself to a specific career choice and a generalized concern for the result of the career decision process, and c) External Conflict - EC scale (5 items), which refers to the individual's difficulty to balance between the importance of his/her own opinion for him/herself and the importance of the relevant opinions of significant others, resulting to the individual's unwillingness to take responsibility for the decision making.

CTI was standardized for the Greek population by Kassotakis, Sidiropoulou-Dimakakou \& Papadakou (2005). The overall estimated internal consistency (Cronbach's $\alpha$ ) for the CTI was .91. The reliability indicators for the subscales are: a) lack of determination and self-estimation, .76, b) confusion in the decision making process (decision making confusion), .86 and c) difficulty in commitment, .80. These three subscales slightly differed from the original CTI ones and were described in the 2005 study through Exploratory Factor Analysis models. In this analysis, the three sub-scales explained $30.1 \%$ of the total variance. In the retrieved structure, the first scale includes 14 statements that express the individual's weakness to take decision-making action explaining $21.37 \%$ of variance. The second dimension includes 19 statements illustrating the individual's weakness to put into practice or to maintain the decision-making process because of his/her weakness to comprehend the procedure itself and its stages; $4.48 \%$ of the variance is explained by this component. The third dimension includes 8 statements expressing the individual's weakness to commit to a decision, i.e., to make a decision or reach a total of alternative solutions, and explains $4.21 \%$ of the total variance. All items are scored on a four-point Likert type scales ( $1=$ strongly disagree to $4=$ strongly agree). It is worth noticing that 7 statements were not a part of any of the three extracted dimensions. The Greek standardization structure was employed in the current analysis.

(b) Career Decision-making Difficulties Questionnaire (CDDQ) (Gati, Krausz \& Osipow, 1996)

The Career Decision-making Difficulties Questionnaire is consisted of 34 items/statements investigating difficulties in decision-making regarding the career path. They are scored on a nine-point Likert type scale (1=does not describe me 9=describes me well). The items are classified in three categories/dimensions: 1) Lack of readiness, 2) Lack of information and 3) Inconsistent information. The first dimension includes three sub-categories of difficulties that may erase prior to the career decision-making process: a) lack of motivation to engage in the career decision-making process, b) general indecision and c) dysfunctional beliefs, which also include irrational expectations about the career decision-making process. The two remaining dimensions include difficulties that may arise during the career decision-making process. The Lack of information dimension includes: a) lack of information about the process, b) lack of information about the self, c) lack of information about the occupations and d) lack of information about the ways of obtaining additional information. Finally, the Inconsistent information dimension includes the following difficulty sub-categories: a) unreliable information, b) internal conflicts and c) external conflicts.

The "Lack of readiness" dimension includes 10 statements, the "Lack of information" dimension includes 12 statements and the "Contradictory information" dimension includes 10 statements. The reliability indicators (internal consistency), during the US standardization were .96 for the whole questionnaire, .92 for the Contradictory Information dimension, .96 for the Lack of Information dimension and .66 for the Lack of Readiness dimension. A concurrent validity check through a cross link with the Career Decision Scale (CDS), assessing professional indecision, reached a satisfactory .77 correlation with the difficulties in the career decision-making CDDQ score. For the sample in this current study, the internal consistency index (Cronbach's $\alpha$ ) for the CDDQ reached .93.

(c) Generalized Self-Efficacy scale (GSE) (Jerusalem \& Schwarzer, 1986, 1992, cf Schwarzer, 1993; Glynou, Schwarzer \& Jerusalem, 1994)

The Generalized Self-Efficacy scale is the revised publication of an older form of the questionnaire by Jerusalem \& Schwarzer (1986, cf Schwarzer, 1993). It consists of 10 questions scored on a four-point Likert type scale, where 1 
means "it never happens" and 4 "it always happens", and the final score is calculated as the sum of the answers. Researchers report that the internal consistency indicators (a) range from .75 to .90 . In respect to the scale's validity, statistically significant differences have been shown for groups evidently different in the self-efficacy that people recognize in themselves (Schwarzer, 1993, cf Argyropoulou, 2004). In previous research conducted by Argyropoulou (2004), the Cronbach $\alpha$, internal consistency index for the total scale reached .77.

(d) Impromptu Questionnaire of individual - demographic elements

Some additional variables were assessed, as demographic and other information (19 questions in all) were considered as directly related to the research objectives. More specifically, the questionnaire included questions on the respondents' gender, study field, and socio-economic background of the student's family. Additionally, the students were asked if they had any form of professional experience, if the profession linked to their degree matched their interests, if they had ever accepted support from Career Orientation Services, if they had already made a specific career decision, and if they had faced problems in making such a decision.

\subsection{Procedure}

Cluster sampling was employed as the data-collection method (see Note 1) with whole University classes recruited as participants. The questionnaires were administered in groups, following brief instructions on the aim of the research project, the importance of participating in it, and on confidentiality credentials. The students' acceptance to complete the questionnaires was thus considered a form of informed consent.

\section{Results}

\subsection{Relations between $C T I$ and $C D D Q$}

Correlations between the CTI and the CDDQ scales are presented in Table 1. Significant positive correlations between CDDQ and CTI factors were found. In summary:

Moderate positive correlations were observed between the total CTI score and: Lack of readiness, Lack of motivation, General indecision, Dysfunctional beliefs, Lack of information about the decision-making process, Lack of information about the self, Lack of information about occupations, Lack of information about the ways of exhibiting additional information, Inconsistent information, Unreliable information, Internal conflicts, External conflicts. Moreover, the CDDQ "Lack of information" dimension correlates highly and positively with the total CTI score and the "Decision-making confusion" score. There is also a moderate positive correlation between "Lack of determination and self-estimation" and: Lack of readiness, General indecision, Dysfunctional beliefs, Lack of information, Lack of information about the decision-making process, Lack of information about the self, Lack of information about occupations, Lack of information about the ways of exhibiting additional information, Inconsistent information, Unreliable information, Internal conflicts, External conflicts. Finally, significant positive correlations between the CTI "Commitment anxiety" dimension and the three CDDQ dimensions (Lack of readiness, Lack of information, Inconsistent information) were found.

$<$ Tables 1 and 2 about here>

The total CTI score and the "Lack of determination and self-estimation" dimension were found to be moderately correlated with many CTI and CDDQ dimensions: Dysfunctional Beliefs, General Indecision, Lack of -readiness -Information about the decision-making process -information about the self -information about occupations -information about the ways of exhibiting additional information, Inconsistent information, Unreliable information, Internal conflicts. In addition, the total CTI score correlated moderately with Lack of motivation and with External conflicts, whereas, the "Lack of determination and self-estimation" dimension also correlated moderately with the "Lack of information" CDDQ dimension, which in turn correlated highly and positively with the total CTI and the "Decision-making confusion" scores. Finally, significant positive correlations between the CTI "Difficulty in Commitment" dimension and all three CDDQ dimensions (Lack of readiness, Lack of information, Inconsistent information) were found.

Simple regression analysis was applied on the CTI dimensions, treated as dependent variables separately. The predictor variable in each model were each of the three main CDDQ dimensions, namely "Lack of Readiness", (b) "Lack of Information" and (c) "Inconsistent Information". The results are summarized in Table 2.

In short, all three CTI dimensions can be "predicted" by the separate CDDQ dimensions in a statistically significant manner and in direct relation to each other, meaning that the more the difficulty in any of the three career decision-making dimensions, the larger the hindrance in career thoughts. The average $r^{2}$ for these nine prediction models was .23, which is higher than expected for simple regression models, showing a moderate direct relation between the CDDQ dimensions and Career Thoughts Inventory dimensions. 


\subsection{Relations between CTI and Generalized Self-Efficacy}

The participants' Generalized Self-Efficacy was analyzed as the total score on the Generalized Self-Efficacy Scale (Glynou, Schwarzer \& Jerusalem, 1994; Jerusalem \& Schwarzer, 1986, 1992, cf Schwarzer, 1993). Two groups (High and Low GSE) were formed according to the overall score on this scale following a median-split. Analysis of variance designs (ANOVA) were conducted with these two GSE groups being the independent variable and the CTI dimensions and the overall score (separately) being the dependent variables. All four designs revealed statistically significant differences between the two groups as follows: (a) in respect to the total CTI score, the Low Self-Efficacy students also showed higher levels of overall career indecision, (b) in respect to the "Lack of determination and self-estimation" dimension, the Low Self-Efficacy students reported higher lack of determination and self-estimation, (c) in respect to the "Confusion in decision-making" dimension, the Low Self-Efficacy students reported higher levels of confusion and (d) in respect to the "Difficulty in commitment" dimension, the Low Self-Efficacy students reported more difficulties (Table 3). According to the $\eta^{2}$ indices, the strongest ones were observed for (a) and (c), that is for the "Confusion in decision making" dimension and for the total CTI score.

\section{$<$ Table 3 about here>}

Analysis of variance (ANOVA) was conducted in order to explore for possible differences in the 13 CDDQ dimension and subscale scores across the two levels of Generalized Self-Efficacy (High vs. Low). The outcomes are not reported in a separate Table; for reasons of brevity and from this point onwards, all CDDQ related results will be described only as in Figure 1. The first left-hand side part of this Figure refers to the comparison of the CDDQ dimensions and subscales across GSE levels. The results ( $F$-ratios for 1 and 258 degrees of freedom) were statistically significant in almost all 13 comparisons ("Dysfunctional beliefs" were not different across the two groups) with $\eta^{2}$ values ranging from .04 to .16 and an average value of .09 , showing that the CDDQ differences across the two GSE groups are moderate to strong ones.

$<$ Figure 1 about here>

Furthermore, and in an attempt to test for the predictive power of the Generalized Self-Efficacy score, simple regression analysis was applied on the CTI dimensions, treated as dependent variables separately. The results are presented in Table 4. In short, all three CTI dimensions can be "predicted" by the GSE score in a statistically significant manner but in an indirect fashion, meaning that the less the Generalized Self-Efficacy, the larger the hindrance in career thoughts. The average $r^{2}$ for these nine prediction models was .12, showing a small indirect relation between GSE and Career Thoughts Inventory dimensions.

$<$ Table 4 about here>

\subsection{Group Differences}

Career decision-making: Students reported whether they had made a specific career decision or not by the time of research, two groups (Yes-No) were formed and then their CTI scores were compared (Student's $t$-criterion). Statistically significant differences were found: (a) in respect to the total CTI score, (b) in respect to the "Confusion in decision-making" dimension, and (c) in respect to the "Difficulty in commitment" dimension, with the students having made a career decision exhibiting a lower score than the students not having made any career decision; this holds true for all three statistically significant differences described above (Table 5).

$<$ Table 5 about here>

Analysis of variance (ANOVA) was further employed in order to explore for possible differences in the 13 CDDQ dimension and subscale scores, this time across the two Career-Decision groups (Made, not Made). The outcomes are reported Figure 1. The second left-hand side part of this Figure refers to the comparison of the CDDQ dimensions and subscales across the two groups. The results ( $F$-ratios for 1 and 258 degrees of freedom) were statistically significant in nine out of the 13 comparisons (with "Dysfunctional beliefs", "Lack of motivations" and "External conflicts" subscales and with "Lack of Readiness" dimension being the same across the groups). Finally, $\eta^{2}$ values ranged from .01 to .06 with an average value of .02 only, showing that the CDDQ differences across the two career-decision groups are weak.

Another analysis of variance model was applied in order to check for possible differences in Generalized Self-Efficacy, by the students' career decision status. A statistically significant difference was present $\left(t=2.375, d f=258, p<.05, \eta^{2}=.02\right)$, with the 101 students having made some career decision exhibiting higher $(m=29.77, s d=3.97)$ Generalized Self-Efficacy than the 159 students not having made any professional decision by that time $(m=28.58, s d=3.94)$.

Personal interests in relation to the vocational domain linked to their Degree: Students reported whether their interests matched the occupation which was related to the University Degree they were studying for. Two groups (Yes-No) were 
formed according to their answers and the CTI dimensions were analyzed as dependent variables through analysis of variance designs (Student's $t$-criterion). Statistically significant differences were found (Table 5) in respect to the total CTI score and also in respect to all dimension scores, with the students reporting a match of their own interests and their occupation as defined by the pursued Degree exhibiting lower scores than the students with unmatched interests.

Analysis of variance was further employed in order to explore for possible differences in the 13 CDDQ dimension and subscale scores, this time across the two Interest-Vocation match groups (match, no match). The outcomes are reported Figure 1. The third cluster of means (starting from the left-hand side) in this Figure refers to the comparison of the CDDQ dimensions and subscales across the two groups. The results ( $F$-ratios for 1 and 258 degrees of freedom) were statistically significant in 11 out of the 13 comparisons (with "Dysfunctional beliefs" and "Lack of Readiness" being the same across the groups). This time, $\eta^{2}$ values ranged from .02 to .11 with an average value of .05 , showing that the CDDQ differences across the two "match" groups are moderate.

Finally, analysis of variance was also applied in order to check for possible differences in Generalized Self-Efficacy by the students' perceived match (Yes or No) of their own interests with the career being determined by their University Degree. A statistically significant difference was present $\left(t=3.456, d f=258, p<.001, \eta^{2}=.04\right)$, with the 217 students who responded to the question positively exhibiting higher $(m=29.41, s d=3.76)$ Generalized Self-Efficacy, than the 43 students who responded that their current University Degrees and the respective careers do not match with their personal interests $(m=27.16, s d=4.58)$.

A few final statistically significant differences were observed when working experience (Yes or No, as reported by the students) groups were compared only in respect to their 13 CDDQ scores. The outcomes are reported Figure 1 (far right-hand side cluster of means). The results ( $F$-ratios for 1 and 258 degrees of freedom) were statistically significant in just four out of the 13 comparisons ("Lack of information", "Lack of information about decision-making", "Lack of information about self", and "Lack of information about ways of obtaining additional information"). The $\eta^{2}$ values ranged from .02 to .04 with an average value of .03, showing that the CDDQ differences across the two "match" groups are weak and mostly referring to the "Lack of information" dimension (and three of its subscales).

\section{Discussion}

In recent years, a gradually growing percentage of students internationally is characterized by career indecision (Lee, 2005). This is evident in the current study as well, as the overwhelming majority of the students declared facing -or having faced- difficulties in career decision-making. The results of the current study have also shown that indecisive students have reported a higher level of dysfunctional thoughts and difficulties than the students that had made a certain career decision. The high correlation between dysfunctional career thoughts and career indecisiveness has been supported widely in research (Reed, Reardon, Lenz \& Leierer, 2001; Austin, Wagner \& Dahl, 2003).

The analysis revealed a statistically significant positive correlation between the CTI factors and lack of information (CDDQ). Numerous researchers have internationally supported that "lack of information" represents one of the main distinctive factors between the vocationally decisive and indecisive students (Pečjak \& Košir, 2007; Germeijs \& De Boeck, 2003). After reviewing the relevant literature, it was clear that inconsistent information and internal/external conflicts as well represent difficulties that are accompanied by career indecision (Pečjak \& Košir, 2007; Constantine \& Flores, 2006). The results of the current study confirmed the aforementioned theoretical expectations. Finally, a set of other theoretical expectations was also confirmed in the present study, when the correlations between the factors of the two scales (CTI, CDDQ) were examined: a) people that are generally deciding with self-confidence and determination do not face any difficulties in career decision-making (Saka \& Gati, 2007; Franken \& Muris, 2005; Germeijs \& De Boeck, 2002), b) lack of motivation represents one of the factors connected to the difficulties in career decision-making (Tak \& Lee, 2003) and c) dysfunctional beliefs negatively influence the ability of career decision-making (Tracey \& Darcey, 2002).

As reflected in the pattern of correlations between the two scales, they have both common and distinctive features. Moving forward, the examination of the "side" correlations leads us to the conclusion that the CDDQ refers to locating the sources of the difficulties preventing the individual from making a decision, while the CTI refers mainly on the consequences those difficulties have. Thus, the two questionnaires function in a complementary way. For example, the CTI subscale "Confusion in decision-making" is highly correlated with the CDDQ "Lack of information". Confusion in decision-making that the person might experience may very well be due to lack of information concerning the procedure or professions. Kleiman, Gati, Peterson, Sampson, Reardon \& Lenz (2004) also reached the same conclusion as they examined relations between the measurements of the two tools, the Career Thoughts Inventory (CTI) and the Career Decision-making Difficulties Questionnaire (CDDQ). The aforementioned conclusion is partly reinforced by the results of our regression analysis and the predictive power present. 
Students agree that any form of vocational experience helps in the recognition of their capacities and interests and facilitates career decision-making (Lent, Brown, Talleyrand, McPartland, Davis, Chopra et al., 2002; Bubany, Krieshok, Black \& McKay, 2008). In the present study, cross-checking of the statistical significance for the CDDQ differences, by levels of vocational experience, has shown that the students who have some form of vocational experience tend to report lower rates in respect to "Lack of information", "Lack of information about decision-making", "Lack of information about self", "Lack of information about ways of obtaining additional information". Thus, vocational experience seems to facilitate career decision-making, as it blocks difficulties that may result from lack of self-information, for the process itself and the ways to search for information. So, the findings of the present study not only confirm, but also add to the initial literature conclusions.

Students whose vocational domain (defined by the pursued Degree) matches their interests, seem less prone to career indecision (as their overall CTI and the dimension scores are lower). This holds true for nearly all CDDQ dimensions and subscales. Thus, students experience overall fewer difficulties in their decision-making process when the vocational domain linked to their Degree matches their interests. Definite requirements for this are ample self-knowledge and psychological stability, consequently less dependence from others and more efficient confrontation of difficulties and dilemmas related to career decision-making processes (Morera, Maydeu-Olivers, Nygren, White, Fernandez \& Skewes, 2006). This conclusion reinforces our opinion that one of the sources of indecision is "value unclarity", which means that probably the person's goals are not clear (Germeijs \& De Boeck, 2003). Also, this conclusion favors the opinion that in order to choose the suitable specialty, it is necessary, not only to have the relevant information, but also to help a person realize his/her interests, to know him/herself (Kassotakis, 2002; Sidiropoulou - Dimakakou, 2010; Nathan \& Hill, 2006).

According to Bandura (1997), between the perception of self-efficacy in a specific behavior and the generalized perception of self-efficacy, an "internal", dependent relation is created, while it is found that the generalized self-efficacy shows the highest cross-relation with the self-efficacy factor in career decision-making (Betz \& Klein, 1996). So, it is expected that there will be a systematic fluctuation in career indecision due to the influence of generalized self-efficacy. This hypothesis was verified by this study, as it was shown that the students that possess a high self-efficacy level exhibit less dysfunctional thoughts and difficulties in career decision-making. The regression analysis results highlighted this conclusion. Our findings comply with research reporting negative correlations between self-efficacy and career indecision (Betz \& Luzzo, 1996; Betz, Klein \& Taylor, 1996).

Nauta (2007), in her study, reported that a highly positive correlation exists between the satisfaction that students feel from the field of their studies and self-efficacy in the decision-making process. In the present study, the students who declare that the vocational domain linked to their Degree matches their interests, exhibit higher generalized self-efficacy than the students for whom interests do not match. It is possible that students face career choice and take the challenge. So those who draw satisfaction from their educational choice and the vocational domain linked to it, are more prone to feel that they are ready to proceed to effective choices. In contrast, the students who are not satisfied by their educational choices may interpret lack of satisfaction as a disability in decision-making and consequently they may feel less capable during the process of career decision-making.

\section{Counseling Implications}

Conclusions and suggestions need to be focused on the practical application of Career Counseling during the transition of young people from Higher Education to the labor market.

Initially, the evaluation of difficulties in career decision-making is especially useful in career counseling, as it can lead to planning of suitable services of career guidance, in order to hopefully lead the person to a more desirable career path. As it was clear in the present study, CTI and CDDQ function complementary to each other. Thus, the simultaneous use of these two questionnaires by the counselor, during counseling evaluation, ensures reliability of assessment and better insight regarding problems in career decision-making.

Self-efficacy theory supports the negative correlation of the construct with career indecision. Therefore, low scores in generalized self-efficacy may suggest intervention aiming to its intensification. Reinforcing self-efficacy, in regard to the confrontation of problems in career decision-making, can give students the chance to confront themselves and the changes that occur in their life in a positive way (Lent, Hackett \& Brown, 1999) and to find solutions by functioning as co-creators of their career decisions. Reinforcing the perception concerning students' personal sufficiency, through various activities and counseling services, can lead to the restructuring of self-efficacy perceptions in respect to new activities, to the development of skills in searching information and to the configuration of their vocational identity.

This study highlighted the students' high personal interest for the vocational domain linked to their Degree, as a factor 
relative to the absence of difficulties in the decision-making process, but also to the enhanced perception of self-efficacy. In this sense, the reinforcement of young people's self-knowledge, even during their studies in Higher Education, will enable them to discover choices that correspond to their interests, by reinforcing in that way their self-efficacy and by facilitating their transition into the labor market. So, it is indispensable that the career counselors help young people to identify their personal characteristics, their interests, their preferences; then, these young people can be systematically informed about the labor market itself.

\section{Limitations}

The present study evaluated -for the first time in the Greek setting- the obstacles that students face when making career decisions, with the use of the CTI and CDDQ questionnaires. However, it has not addressed all aspects and there is still a long research-way to go. A drawback in our study was that we recruited students of an Economic University only when gathering the research information; it would certainly be important to extend our research to Greek students in different scientific disciplines, in the future.

Furthermore, although the present study has shown a statistically significant correlation between self-efficacy and obstacles in the decision-making process, the question regarding causal relationships between these concepts remains unanswered. This has not been resolved in the literature as well, as numerous research supports that self-efficacy precedes career indecision (Guay, Senécal, Gauthier \& Fernet, 2003), while others support that there is no causal relation and that other factors intervene, such as vocational interests, goals or expectations of results (Creed, Patton \& Prideaux, 2006). This causal relationship issue may require further research attention, possibly through structural equation modelling to assess the relative importance of extraneous factors and decide on the temporal order of the constructs involved.

\section{References}

Anastasi, A. (1990). Psychological Testing (6 $6^{\text {th }}$ Edition). New York: Macmillan Publishing Company.

Argyropoulou, K. (2004). The role of self-efficacy in the career decision-making process for $2^{\text {nd }}$ and $3^{\text {rd }}$ Grade High School students' professional choices. Unpublished manuscript. National and Kapodistrian University of Athens, School of Philosophy, Faculty of Philosophy, Pedagogy and Psychology, Athens (In Greek).

Argyropoulou, K., Sidiropoulou-Dimakakou, D., \& Besevegis, E. (2007). Generalized Self-Efficacy, Coping, Career Indecision, and Vocational Choices of Senior High School Students in Greece: Implications for Career Guidance Practitioners. Journal of Career Development, 33 (4), 316-337. http://dx.doi.org/10.1177/0894845307300412.

Austin, R.K. (2005). The relationship between career thinking and salutogenic functioning. Dissertation. [Online] Available: http://etd.unisa.ac.za/ETD-db/theses/available/etd-06192006-110331/unrestricted/thesis.pdf (June 9, 2008).

Austin, R.K., Wagner, B., \& Dahl, D. (2003). Reducing negative career thoughts in adults. International Journal of Disability Community and Rehabilitation, 2, (2). [Online] Available: http://www.ijdcr.ca/VOL02_02_CAN/articles/austin.shtml (June 7, 2008)

Bandura, A. (1977). Self-efficacy: Toward a unifying theory of behavior change. Psychological Review, 84 (2), 191-215.

Bandura, A. (1997). Self-Efficacy Theory. The exercise of control. New York: W.H. Freeman \& Company.

Bandura, A., Barbaranelli, C., Caprara, G.V., \& Pastorelli C. (2001). Self-Efficacy Beliefs as Shapers of Children's Aspirations and Career Trajectories. Child Development, 72 (1), 187-206. http://dx.doi.org/10.1111/1467-8624.00273

Betz, N., \& Klein, K. (1996). Relationships among measures of career self-efficacy, generalized self-efficacy and global self-esteem. Journal of Career Assessment, 4 (3), 285-298. http://dx.doi.org/10.1177/106907279600400304

Betz, N.E., Klein, K.L., \& Taylor, K.M. (1996). Evaluation of a Short Form of the Career Decision-Making Self Efficacy Scale. Journal of Career Assessment, 4 (3), 47-57. http://dx.doi.org/10.1177/106907279600400103

Betz, N.E., \& Luzzo, D. A. (1996). Career assessment and the Career Decision-Making Self- Efficacy Scale. Journal of Career Assessment, 4 (4), 413-428. http://dx.doi.org/10.1177/106907279600400405

Betz, N.E., \& Voyten, K. (1997). Efficacy and outcome expectations influence career exploration and decidedness. The Career Development Quarterly, 46 (2), 179-189.

Bubany, S., Krieshok, T., Black, M., \& McKay, R. (2008). College Students' Perspectibeliefs on Their Career Decision Making. Journal of Career Assessment, 16, 177 - 197. 
Constantine, M., \& Flores, L. (2006). Psychological Distress, Perceived Family Conflict and Career Development Issues in College Students of Color. Journal of Career Assessment, 14 (3), 354-369. http://dx.doi.org/10.1177/1069072706286491

Creed, P. A., \& Patton, W. (2003). Predicting two components of career maturity in school based adolescents. Journal of Career Development, 29 (4), 277-290. http://dx.doi.org/10.1177/089484530302900405

Creed, P., Patton, W., \& Prideaux, L. (2006). Causal Relationship Between Career Indecision and Career Decision-Making Self-Efficacy: A Longitudinal Cross-Lagged Analysis. Journal of Career Development, 33 (1), 47-65.

Dimitropoulos, E. (2003). Decisions \& Decision-Making. Athens: Grigoris (In Greek).

Dryden, W. (1979). Rational-emotive therapy and its contribute.ons to careers counseling. British Journal of Guidance and Counseling, 7 (2), 181-187.

Franken, I. H. A., \& Muris, P. (2005). Individual differences in decision making. Personality and Individual Differences, 39 (5), 991-998. http://dx.doi.org/10.1016/j.paid.2005.04.004

Gati, I., Krausz, M., \& Osipow, S.H. (1996). A taxonomy of difficulties in career decision making. Journal of Counseling Psychology, 43, 510-526.

Gati, I., \& Saka, N. (2001). Career-related decision-making difficulties of high-school students. Journal of Counseling and Development, 79 (3), 331-340.

Germeijs, V., \& De Boeck, P. (2002). A measurement scale for indecision and its relationship to career indecision and other types of indecision. European Journal of Psychological Assessment, 18 (2), 113-122. http://dx.doi.org/10.1027//1015-5759.18.2.113

Germeijs, V., \& De Boeck, P. (2003). Career Indecision: Three factors from decision theory. Journal of Vocational Behavior, 62 (1), 11-25. http://dx.doi.org/10.1016/S0001-8791(02)00055-6

Glynou, E., Schwarzer, R., \& Jerusalem, M. (1994). Greek Adaptation of the Generalized Self-Efficacy Scale. [Online] Available: http://userpage.fu-berlin.de/ health/greek.htm (June 10, 2008).

Guay, F., Senécal, C., Gauthier, L., \& Fernet, C. (2003). Predicting career indecision: A self-determination theory perspective. Journal of Counseling Psychology, 50, 165-177. http://dx.doi.org/10.1037/0022-0167.50.2.165

Kantas A., \& Hantzi A. (1991). Psychology of Work - Theories of Career Development - Counseling Basics. Athens: Ellinika Grammata (In Greek).

Kassotakis, M. (2002). Counseling and Career Guidance: Conceptual Entries, Objectives and Targets.

In Kassotakis, M. (Ed.). Counseling and Career Guidance - Theory and Practice (pp. 43-59). Athens: Tipothito (In Greek).

Kassotakis, M., Sidiropoulou-Dimakakou, D., \& Papadakou, P. (2005). Enquiry of Negative Career Thoughts of high school students using the Career Thoughts Questionnaire. Unpublished manuscript. National and Kapodistrian University of Athens, School of Philosophy, Faculty of Philosophy, Pedagogy and Psychology, Athens (In Greek).

Kelly, K. R., \& Lee, W. C. (2002). Mapping the domain of career decision problems. Journal of Vocational Behavior, 41, $302-326$.

Kleiman, T., Gati, I., Peterson, G., Sampson, J., Reardon, R., \& Lenz, J. (2004). Dysfunctional Thinking and Difficulties in Career Decision Making. Journal of Career Assessment, 12 (3), 312-331. http://dx.doi.org/10.1177/1069072704266673

Krumboltz, J.D. (1994). The Career Beliefs Inventory. Journal of Counseling and Development, 72 (4), 424-428.

Lee, K. (2005). Coping with Career Indecision: Differences between Four Career Choice Types. Journal of Career Development, 31 (4), 279-289.

Lent, R. W., Brown, S. D., Talleyrand, R., McPartland, E. B., Davis, T., Chopra, S. B. et al. (2002). Career choice barriers, supports, and coping strategies: College students' experiences. Journal of Vocational Behavior, 60 (1), 61-72. http://dx.doi.org/10.1006/jvbe.2001.1814

Lent, R. W., \& Hackett, G. (1994). Sociocognitive Mechanisms of Personal Agency in Career Development. In Savickas, M.L., \& Lent, R.W. (Eds.). Convergence in Career Development (pp. 77-103). California: Palo Alto.

Lent, R.W., Hackett, G., \& Brown, S.D. (1999). A social cognitive view of the school-to-work transition. Career 
Development Quarterly, 47, 297-311.

McWhirter, E. H., Rasheed, S., \& Crothers, M. (2000). The effects of high school career education on social cognitive variables. Journal of Counseling Psychology, 47 (3), 330-341.

Morera, O. F., Maydeu-Olivares, A., Nygren, T. E., White, R. J., Fernandez, N. P., \& Skewes, M. C. (2006). Social problem solving predicts decision-making styles among US Hispanics. Personality and Individual Differences, 41 (2), 307-317. http://dx.doi.org/10.1016/j.paid.2005.08.016

Nathan, R., \& Hill, L. (2006). Career Counseling. London: Sage

Nauta, M. (2007). Assessing College Students' Satisfaction With Their Academic Majors. Journal of Career Assessment, 15 (4), 446 - 462. http://dx.doi.org/10.1177/1069072707305762.

Osipow, S. H. (1999). Assessing career indecision. Journal of Vocational Behavior, 55, 147-154.

Paraskevopoulos, J. N. (1993). Research Methods in Science. Athens (In Greek).

Pečjak, S., \& Košir, K. (2007). Personality, Motivational Factors and Difficulties in Career Decision-Making in Secondary School Students. Psihologijske teme 16 (1), 141-158.

Reed, C., Reardon, R., Lenz, J., \& Leierer, S. (2001). Reducing negative career thoughts with a career course. Career Development Quarterly, 50 (2), 158-167.

Roll, T., \& Arthur, N. (2002). Beliefs in career counselling. Proceedings of the National Consultation on Career Development. [Online] Available: http://www.contactpoint.ca/natcon-conat/2002/pdf/pdf-02-03.pdf (June 9, 2008).

Saka, N., \& Gati, I. (2007). Emotional and personality-related aspects of persistent career decision-making difficulties. Journal of Vocational Behavior, 71, 340-358.

Sampson, J.P., Jr., Peterson, G.W., Lenz, J.G., Reardon, R.C., \& Saunders, D.E. (1996). Career Thoughts Inventory: Professional manual. Odessa, FL: Psychological Assessment Resources, Inc.

Sampson, J.P., Jr., Peterson, G.W., Lenz, J.G., Reardon, R.C., \& Saunders, D.E. (1998). The design and use of a measure of dysfunctional career thoughts among adults, college students, and high school students: The Career Thoughts Inventory. Journal of Career Assessment, 6 (2), 115-134. http://dx.doi.org/10.1177/106907279800600201.

Saunders, D., Peterson, G., Sampson, J., \& Reardon, R. (2000). Relation of Depression and Dysfunctional Career Thinking to Career Indecision. Journal of Vocational Behavior, 56 (2), 288-298. http://dx.doi.org/10.1006/jvbe.1999.1715.

Schwarzer, R. (1993). Measurement of Perceived Self- Efficacy. Psychometric Scales for Cross-Cultural Research. Berlin: Forschung an der Frein Universität

Sidiropoulou - Dimakakou, D. (1995). The educational and vocational information in today's school : Necessity, effective use, means for the communication of information, Nea Paideia 75, 137-148 (In Greek).

Sidiropoulou - Dimakakou, D. (2010). Career Assessment. Athens: Metaichmio (In Greek).

Tak, J. K., \& Lee, K. H. (2003). Development of the Korean Career Indecision Inventory. Journal of Career Assessment, $11,328-345$.

Thompson, M., \& Subich, L. (2006). The relation of social status to the career decision-making process. Journal of Vocational Behavior 69 (2), 289-301. http://dx.doi.org/ 10.1016/j.jvb.2006.04.008

Tracey, J. G., \& Darcey, M. (2002). An idiothetic examination of vocational interests and their relation to career decidedness. Journal of Counseling Psychology, 49 (4), 420-427.http://dx.doi.org/10.1037/0022-0167.49.4.420

\section{Notes}

Note 1. According to Paraskevopoulos (1993), the above selection procedure is not "random to the end", since it does not allow under the same probabilistic potential for all population members to become members of the sample. However, it retains plausibility in respect to sample representativeness and has many practical advantages, also circumventing many bureaucratic processes and obstacles. 
Table 1. Pearson $r$ indices between Career Thoughts and Career Decision-making Difficulties

\begin{tabular}{|c|c|c|c|c|c|c|c|c|c|c|c|c|c|c|c|c|c|}
\hline & $\mathbf{1}$ & 2 & 3 & 4 & 5 & 6 & 7 & 8 & 9 & 10 & 11 & 12 & 13 & 14 & 15 & 16 & 17 \\
\hline 1. Total CTI & 1 & & & & & & & & & & & & & & & & \\
\hline $\begin{array}{l}\text { 2. Lack of determination } \\
\text { and self-estimation }\end{array}$ & .86 & 1 & & & & & & & & & & & & & & & \\
\hline 3. Confusion in decision making & .90 & .64 & 1 & & & & & & & & & & & & & & \\
\hline 4. Difficulty in commitment & .76 & .59 & .57 & 1 & & & & & & & & & & & & & \\
\hline 5. Lack of readiness & .47 & .41 & .46 & .30 & 1 & & & & & & & & & & & & \\
\hline 6. Lack of motivation & .25 & .10 & .33 & .20 & .61 & 1 & & & & & & & & & & & \\
\hline 7. General indecision & .45 & .42 & .40 & .31 & .65 & .15 & 1 & & & & & & & & & & \\
\hline 8. Dysfunctional beliefs & .25 & .29 & .20 & .11 & .70 & .09 & .19 & 1 & & & & & & & & & \\
\hline 9. Lack of information (LOI) & .64 & .53 & .62 & .47 & .55 & .39 & .48 & .24 & 1 & & & & & & & & \\
\hline 10. LOI about decision-making & .59 & .51 & .57 & .40 & .52 & .31 & .47 & .28 & .82 & 1 & & & & & & & \\
\hline 11. LOI about self & .58 & .45 & 61 & .40 & .52 & .40 & .42 & .23 & .90 & .64 & 1 & & & & & & \\
\hline 12. LOI about occupations & .51 & .44 & .46 & .42 & .42 & .30 & .40 & .14 & .87 & .59 & .67 & 1 & & & & & \\
\hline $\begin{array}{l}\text { 13. LOI about ways of obtaini } \\
\text { additional information }\end{array}$ & .51 & .46 & .47 & .40 & .42 & .30 & .37 & .19 & .87 & .61 & .71 & .77 & 1 & & & & \\
\hline 14. Inconsistent information & .58 & .41 & 60 & .45 & .50 & .41 & .45 & .15 & .74 & .55 & .70 & .64 & .68 & 1 & & & \\
\hline 15. Unreliable information & .53 & .40 & .53 & .45 & .48 & .36 & .44 & .19 & .70 & .51 & .68 & .57 & .66 & .88 & 1 & & \\
\hline 16. Internal conflicts & .55 & .37 & .57 & .44 & .43 & .37 & .39 & .12 & .67 & .51 & .60 & .60 & .61 & .93 & .71 & 1 & \\
\hline 17. External conflicts & .40 & .27 & .44 & .23 & .39 & .34 & .35 & .10 & .55 & .40 & .53 & .47 & .48 & .78 & .58 & .62 & 1 \\
\hline
\end{tabular}

All indices are statistically significant at the .01 level except for two uderlined indices, for which $p<.05$; non-significant indices are shown in italics.

Table 2. Regression analysis results: predictive power of the CDDQ dimensions over the CTI dimensions

\begin{tabular}{|c|c|c|c|c|}
\hline $\begin{array}{l}\text { Dependent } \\
\text { variable }\end{array}$ & $\begin{array}{c}\text { Independent } \\
\text { variable }\end{array}$ & Regression Equation & $b$ - lower limit & $b$ - upper limit \\
\hline \multirow{3}{*}{$\begin{array}{l}\text { Lack of } \\
\text { determination and } \\
\text { self-estimation }\end{array}$} & Lack of readiness & $\mathrm{Y}_{\text {predicted }}=24.792+.19 \mathrm{X}$ & .139 & .243 \\
\hline & Lack of information & $\mathrm{Y}_{\text {predicted }}=26.075+.14 \mathrm{X}$ & .113 & .168 \\
\hline & Inconsistent information & $Y_{\text {predicted }}=28.083+.14 \mathrm{X}$ & .100 & .175 \\
\hline \multirow{3}{*}{$\begin{array}{l}\text { Confusion in the } \\
\text { decision-making }\end{array}$} & Lack of readiness & $\mathrm{Y}_{\text {predicted }}=23.868+.30 \mathrm{X}$ & .232 & .375 \\
\hline & Lack of information & $\mathrm{Y}_{\text {predicted }}=25.551+.23 \mathrm{X}$ & .195 & .267 \\
\hline & Inconsistent information & $\mathrm{Y}_{\text {predicted }}=26.715+.28 \mathrm{X}$ & .237 & .330 \\
\hline \multirow{3}{*}{$\begin{array}{l}\text { Difficulty in } \\
\text { commitment }\end{array}$} & Lack of readiness & $\mathrm{Y}_{\text {predicted }}=14.260+.10 \mathrm{X}$ & .058 & .132 \\
\hline & Lack of information & $\mathrm{Y}_{\text {predicted }}=14.216+.08 \mathrm{X}$ & .065 & .103 \\
\hline & Inconsistent information & $\mathrm{Y}_{\text {predicted }}=14.711+.10 \mathrm{X}$ & .076 & .126 \\
\hline
\end{tabular}


Table 3. Descriptive statistics and analysis of variance results for the CTI scores by levels of GSE

\begin{tabular}{|c|c|c|c|c|c|c|}
\hline Dependent Variables & $\begin{array}{c}\text { Level of Generalized } \\
\text { Self-Efficacy }\end{array}$ & $N$ & $M$ & S.D. & $F$ & $\eta^{2}$ \\
\hline \multirow{3}{*}{ Total CTI } & High & 125 & 98.70 & 15.89 & \multirow{3}{*}{37.213} & \multirow{3}{*}{.13} \\
\hline & Low & 135 & 109.54 & 12.67 & & \\
\hline & Total & 260 & 104.33 & 15.28 & & \\
\hline \multirow{3}{*}{ Lack of determination and self-estimation } & High & 125 & 31.70 & 5.68 & \multirow{3}{*}{16.428} & \multirow{3}{*}{.06} \\
\hline & Low & 135 & 34.17 & 4.09 & & \\
\hline & Total & 260 & 32.98 & 5.06 & & \\
\hline \multirow{3}{*}{ Confusion in the decision making } & High & 125 & 33.97 & 6.56 & \multirow{3}{*}{46.578} & \multirow{3}{*}{.15} \\
\hline & Low & 135 & 39.54 & 6.60 & & \\
\hline & Total & 260 & 36.86 & 7.13 & & \\
\hline \multirow{3}{*}{ Difficulty in commitment } & High & 125 & 17.58 & 3.59 & \multirow{3}{*}{12.108} & \multirow{3}{*}{.04} \\
\hline & Low & 135 & 19.02 & 3.10 & & \\
\hline & Total & 260 & 18.33 & 3.42 & & \\
\hline
\end{tabular}

All $F$-ratios for 1 and 258 degrees of freedom were statistically significant at the .001 level.

Table 4. Regression analysis results: predictive power of Generalized Self-Efficacy over the CTI dimensions

\begin{tabular}{|l|c|c|c|}
\hline \multicolumn{1}{|c|}{ Dependent variable } & Regression Equation & $b$ - lower limit (95\%) & b - upper limit $_{\text {(95\%) }}$ \\
\hline Lack of determination and self-estimation & $\mathrm{Y}_{\text {predicted }}=44.599+(-.40 \mathrm{X})$ & -.548 & -.252 \\
\hline Confusion in the decision-making & $\mathrm{Y}_{\text {predicted }}=61.006+(-.14 \mathrm{X})$ & -1.025 & -.637 \\
\hline Difficulty in commitment & & & -.302 \\
\hline
\end{tabular}

Table 5. Descriptive statistics and analysis of variance (Student's $t$-criterion) for the CTI scores by a) career decision status b) matching of interests with Degree related career

\begin{tabular}{|c|c|c|c|c|c|c|c|}
\hline Dependent Variables & $\begin{array}{l}\text { Have you made any specific career } \\
\text { decision? }\end{array}$ & $N$ & $M$ & S.D. & $t$ & $p$ & $\eta^{2}$ \\
\hline \multirow{2}{*}{ Total CTI } & Yes & 101 & 101.14 & 14.54 & \multirow{2}{*}{-2.709} & \multirow{2}{*}{$<.01$} & \multirow{2}{*}{.03} \\
\hline & No & 159 & 106.35 & 15.43 & & & \\
\hline \multirow{2}{*}{$\begin{array}{l}\text { Lack of determination and } \\
\text { self-estimation }\end{array}$} & Yes & 101 & 32.37 & 5.15 & \multirow{2}{*}{-1.670} & \multirow{2}{*}{$\mathrm{ns}$} & \multirow{2}{*}{.01} \\
\hline & No & 159 & 33.44 & 4.96 & & & \\
\hline \multirow{2}{*}{$\begin{array}{l}\text { Confusion in the decision } \\
\text { making }\end{array}$} & Yes & 101 & 35.40 & 6.58 & \multirow{2}{*}{-2.667} & \multirow{2}{*}{$<.01$} & \multirow{2}{*}{.03} \\
\hline & No & 159 & 37.79 & 7.32 & & & \\
\hline \multirow{2}{*}{ Difficulty in commitment } & Yes & 101 & 17.29 & 3.36 & \multirow{2}{*}{-4.013} & \multirow{2}{*}{$<.001$} & \multirow{2}{*}{.06} \\
\hline & No & 159 & 18.99 & 3.29 & & & \\
\hline
\end{tabular}




\begin{tabular}{|c|c|c|c|c|c|c|c|}
\hline Dependent Variables & $\begin{array}{l}\text { Matching of interests with vocational } \\
\text { domain related to pursued Degree }\end{array}$ & $N$ & $M$ & S.D. & $t$ & $p$ & $\eta^{2}$ \\
\hline \multirow{2}{*}{ Total CTI } & Yes & 217 & 102.41 & 14.96 & \multirow{2}{*}{-4.713} & \multirow{2}{*}{$<.001$} & \multirow{2}{*}{.08} \\
\hline & No & 43 & 113.97 & 13.18 & & & \\
\hline \multirow{2}{*}{$\begin{array}{l}\text { Lack of determination and } \\
\text { self-estimation }\end{array}$} & Yes & 217 & 32.63 & 5.18 & \multirow{2}{*}{-2.550} & \multirow{2}{*}{$<.01$} & \multirow{2}{*}{.02} \\
\hline & No & 43 & 34.76 & 4.00 & & & \\
\hline \multirow{2}{*}{$\begin{array}{l}\text { Confusion in the decision } \\
\text { making }\end{array}$} & Yes & 217 & 35.76 & 6.73 & \multirow{2}{*}{-6.144} & \multirow{2}{*}{$<.001$} & \multirow{2}{*}{.12} \\
\hline & No & 43 & 42.44 & 6.50 & & & \\
\hline \multirow{2}{*}{ Difficulty in commitment } & Yes & 217 & 18.09 & 3.36 & \multirow{2}{*}{-2.547} & \multirow{2}{*}{$<.01$} & \multirow{2}{*}{.02} \\
\hline & No & 43 & 19.53 & 3.46 & & & \\
\hline
\end{tabular}

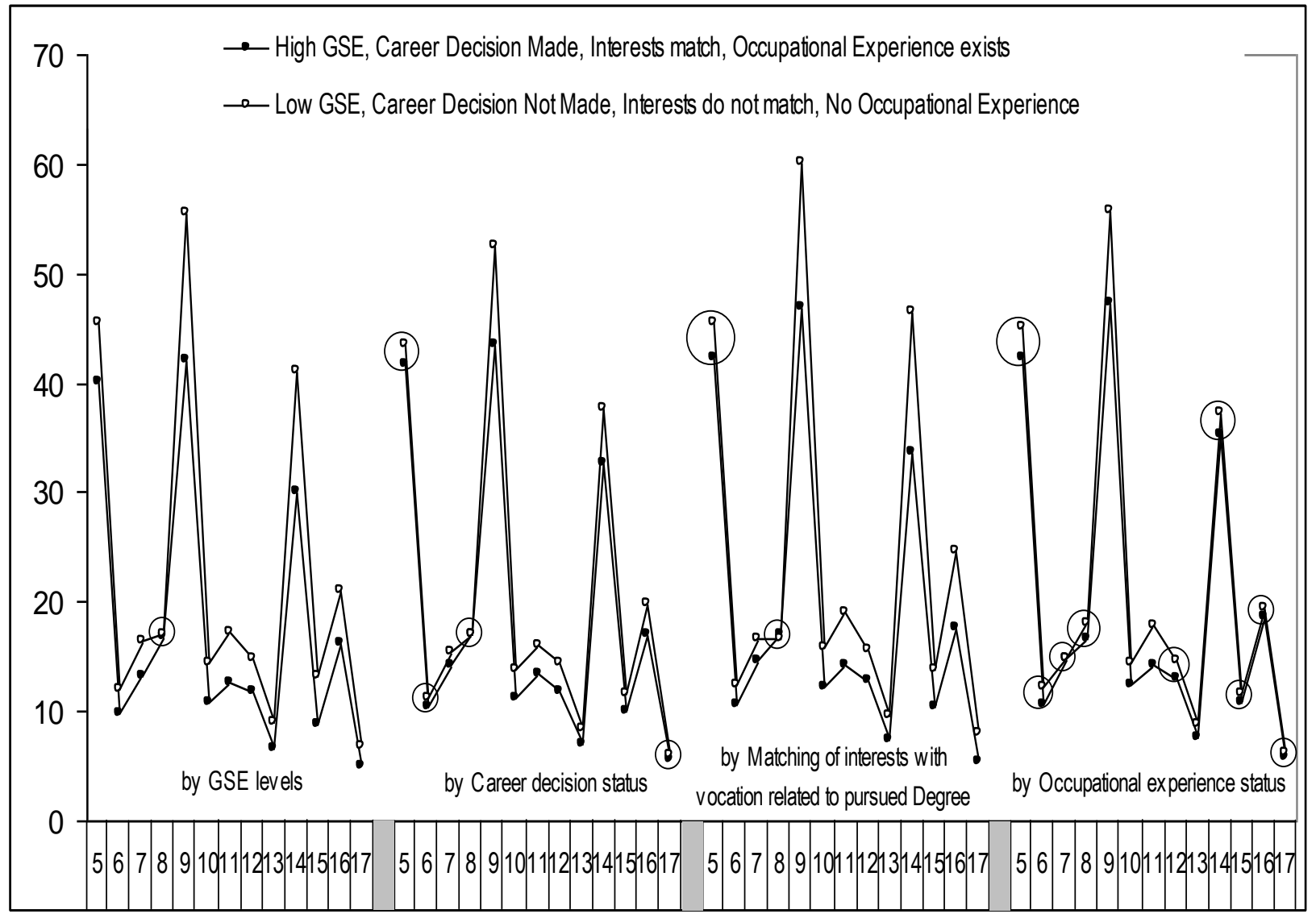

Figure 1. Mean scores for the CDDQ dimensions and subscales by four groupings according to GSE, Career Decision status, Matching or not of personal interests with occupation related to pursued Degree and, existence or not of Occupational experience.

Notes:

-Digits 5 to 17 correspond to the 13 CDDQ main dimensions and their sub-scales as these have been presented in Table 1.

-All dimensions and subscales are of different score range, thus the lines drawn are merely a practical aid in "reading" the figure and do not correspond to differences across dimensions and subscales.

-All differences across groups are statistically significant except for those depicted in circles. The "Dysfunctional beliefs" subscale differences across groups were not significant in any of the comparisons attempted; the "Lack of Readiness" dimension differences across groups were not significant in three out of four comparisons, etc.

-The least differentiating factor is the Occupational experience one and the most differentiating is the GSE-level grouping 